Revised for the Journal of Happiness Studies 22nd April 2013

JOHS-D-12-01282R2

\title{
A demonstration of set-points for subjective wellbeing
}

\author{
Robert A. Cummins ${ }^{1}$, Ning Li $^{2}$, Mark Wooden ${ }^{2}$ \& Mark Stokes ${ }^{1}$ \\ ${ }^{1}$ School of Psychology, Deakin University \\ ${ }^{2}$ Melbourne Institute of Applied Economic and Social Research, University of Melbourne
}

\begin{abstract}
This paper presents evidence for the existence of 'set-points' for subjective wellbeing. Our results derive from a 10-year longitudinal study in which subjective wellbeing has been measured using a single question of general life satisfaction. The process of data analysis is driven by logic based on the theory of subjective wellbeing homeostasis. This analysis involves the iterative elimination of raw data, from 7,356 individual respondents, based on confidence limits. All results are projected onto a $0-100$ point scale. We demonstrate evidence for the existence of set-points lying between $71-90$ points, with an average setpoint-range of $18-20$ points for each person. The implications and limitations of these findings are discussed.
\end{abstract}

\section{Introduction}

This paper concerns the topic of 'set-points' in Subjective Wellbeing (SWB). Setpoints are conceived as a genetically determined, individual difference for each individual, which strongly influences each person's normal level of SWB. Their existence has been hotly debated. This introduction presents an historical outline of the influences driving theory development in this area, and also examines empirical support for both sides of this debate. In allowing this description without an over-attention to measurement detail, a fairly catholic view has been taken of what constitutes SWB. It is used in a manner inclusive of positive mood affect, a single question on satisfaction with life as a whole, and scales based on satisfaction with life domains.

\section{SWB stability}

The first requirement for scientific measurement is that empirical estimates of the phenomenon under examination can be made reliably. This was first achieved in relation to SWB over 80 years ago when Watson (1930) found that self-ratings on a printed rating scale 
correlated .81 with a composite score comprising a number of indices. He concluded that the general level of happiness can be measured with adequate reliability using such a scale.

Not long after this it was discovered that measures of mood happiness were surprisingly stable over time. For example, Hartmann (1934) obtained a test-retest reliability of .70 with two testings a month apart, while Wessman and Ricks (1966, p. 103) reported that happiness-related measures taken 2 years apart correlated .67. By the late 1970s it was clear that there was considerable stability in SWB, with significant retest correlations being reported over substantial periods (Andrews \& Withey, 1976; Palmore \& Kivett, 1977).

Before long, researchers started to ask what might be the cause of such trait stability in SWB and looked to personality for their answer. After all, there was a conventional view that personality was largely genetically determined (for reviews see Block, 1981; Brim \& Kagan, 1980; Jackson \& Paunonen, 1980) and because of this it was stable. Thus, if personality was strongly linked to SWB, it would be the likely cause of SWB stability.

\section{Personality and SWB}

The contemporary view of happiness being strongly related to the personality dimensions of extraversion and neuroticism has a long history. It was Sailer (1931) who first observed that evenness of temperament was the factor which best discriminated between people who were happy or unhappy. Other early researchers also reported that mood happiness correlated with sociability and emotional stability (e.g. Smith, 1961; Wessman \& Ricks, 1966). From his review of this early literature, Wilson (1967) concluded "Perhaps the most impressive single finding lies in the relation between happiness and successful involvement with people" (p. 304), thus supporting the happiness-extraversion connection.

In more recent times, Costa and McCrae (1980) consolidated the personality connection. Their studies confirm that people tend to stay at the same relative level of happiness over long periods of time and state: "This relative stability in well-being is most easily interpreted as an outcome of the stability of personality dimensions [neuroticism and extraversion] that underlie characteristic levels of happiness" (p. 677). This conclusion stimulated opposition from people who, for various reasons, scientific and otherwise, were repelled by the idea of fixed levels of happiness.

Leading this oppositional charge were Headey and Wearing $(1989,1992)$. Using data from their 4-wave Australian longitudinal study they dismiss the Costa and McCrae (1980; 1984) proposition because this would mean that people's level of SWB "would remain virtually unchanged over their entire lifetimes" (1992, p. 145), which their own data showed was not correct. They suggest the alternative that, while each person has an 'equilibrium level' of SWB, it can be moved from this level by strong life events. Personality, they argue, has the role of restoring equilibrium by generating probabilities for particular kinds of life events. For example, people with strong extraversion have a higher than normal probability of experiencing positive events. Thus, personality, life events, and SWB are in dynamic equilibrium with one another, they claim. 
This model is, however, incomplete. First, Costa and McCrae never suggest the stability of SWB denies people the experience of ecstasy and despair through life events. Their concern is only with long-term SWB stability. Second, Headey and Wearing never really explain how, after a deviation from equilibrium caused by an event, SWB returns to its previous level. The assumption seems to be that, if someone high on extraversion experiences low SWB due to an adverse event, they will recover because their personality will necessarily expose them to counteracting positive events. However, if someone who scores high on neuroticism experiences abnormally low SWB due to a negative event, the personality notion fails to explain how their SWB returns to equilibrium.

For other researchers intrigued by the SWB-personality nexus, it was a small step to link the presumed causal influence of personality with genetics. As stated earlier, it had long been assumed that the stability in personality was due to high genetic determination (for reviews see Tellegen et al., 1988), so it was an interesting question whether SWB was under some degree of genetic determination through personality, or whether a direct link between SWB and genetics could be separately demonstrated.

\section{Genetics, set-points and homeostasis}

It has been received wisdom for over 50 years that emotionality has a strong genetic basis. As Smith (1961, Chapter 6) points out, animals have been bred for differing levels of emotionality. So it did not take long for researchers to study the relative influence of genetics and environment on the SWB of twins. Early studies, however, reported mixed results, in part because researchers had only sampled twins reared together.

Clarification came from Tellegen et al. (1988) who studied both monozygotic (MZ) and dizygotic (DZ) pairs of middle-aged twins either reared together, or separated in infancy and reared apart. Using the Well-Being scale of the Multidimensional Personality Questionnaire (WB-MPQ: unpublished), which measures 'positive emotionality', their best estimate of wellbeing heritability was .48 (SD .08). Moreover, the contribution of a common family environment was negligible.

This result was reinforced by Lykken and Tellegen (1996), who also used the WellBeing scale on DZ and MZ twins, first tested aged about 20 years of age and retested 10 years later. The retest correlation for DZ was .07 and for the MZ .40. They state this latter figure represents " $80 \%$ of the retest correlation of .50 " which they argue "suggests that the stable component of well-being (i.e., trait happiness) is largely determined genetically" (p. 188). They also report combined results on 1,380 pairs of twins, drawn from various USA sources, which essentially replicate the above results. They end with the killer-line: "It may be that trying to be happier is as futile as trying to be taller and therefore is counterproductive" (p. 189).

While the above studies laid a solid foundation for the idea that SWB has a strong genetic influence, they did not combine this information with the evidence of SWB stability, mentioned earlier. This important step was provided by Headey and Wearing $(1989,1992)$ who gave a name to the phenomenon of SWB stability as an individual's 'equilibrium level'. 
This raises the issue of terminology, particularly the distinction between 'baseline', 'equilibrium level' and 'set-point'.

In science, the term 'baseline' refers to an initial reliable measurement against which subsequent measurements may be compared. It carries no connotations of normality. Baseline measures are commonly employed to assess treatment effectiveness where the variable in question (e.g., anxiety) is pathological. Confusingly, however, some researchers, such as Clark, Diener, Georgellis and Lucas (2008), use the term as though 'baseline' represents normality, which is importantly misleading. For example, their Table 1 shows that $18.3 \%$ of the General Life Satisfaction (GLS) scores comprising their sample had a value of 50 points or less, which is pathologically low (Cummins, 2010). Clearly, the interpretation of change will differ depending on whether the baseline measure represents normal or pathological levels of SWB.

The term 'equilibrium level', as introduced by Headey and Wearing $(1989,1992)$, does imply normality. It denotes a level of SWB stability for each person caused by their personality. However, equilibrium levels can change due to 'slowly changing personal characteristics' which may be induced due to chronic changes in wealth (1992, p. 104), social connections (p. 127) or age (p. 130). They regard these as examples "of environment moulding personality" (Headey \& Wearing, 1992, p. 104).

In sharp contrast to both of the above terms, 'set-points' are both normal and genetically set at a constant level. Examples from biology are body temperature and blood calcium levels. They are, therefore, unmodifiable by environmental experience. In terms of SWB, the level at which each set-point operates is an individual difference between people (Lykken \& Tellegen, 1996)

The earliest use of the term 'set-point' comes from McGue, Bacon and Lykken (1993), who do not cite the work of Headey and Wearing. Their study of twins included SWB measured by the WB-MPQ. They confirmed reasonable stability in overall personality between the ages of about 20 and 30 years and state in relation to SWB that "typically within 1 year, sense of well being has returned to its preevent level (i.e., to a stable set point that we hypothesize is predominantly influenced by genetic factors)" (p. 105). Notably, however, McGue et al. did not measure life events in their study, so use as evidence for this statement papers by Brickman, Coates and Janoff-Bulman (1978), Okun, Olding and Cohn (1990), Murrell and Himmelfarb (1989), and Wortman and Silver (1982). These citations offer very weak support for their contention. Two cannot be used to verify the one-year claim of SWB return. No such claim is made by Brickman et al. (1978), while the reference to Wortman and Silver is an unpublished conference paper. Of the other two, Murrell and Himmelfarb (1989) studied depression following bereavement, not SWB, while Okun et al. (1990) studied shortterm intervention effectiveness among people who were institutionalized and elderly. They found the immediate post-intervention rise in SWB had generally disappeared within a month following the intervention. This does not constitute a sustained environmental influence and so is irrelevant to the one-year claim. In summary, the cited references do not support the idea 
of SWB recovery within a year, yet this misleading statement has had a marked effect on subsequent literature, as will be shown.

Two years following this first use of 'set-point', Cummins (1995) reported a high level of consistency in SWB population mean scores derived from different researchers, instruments and countries. He does not cite McGue et al. (1993) but concludes that "the consistency of this phenomenon across widely differing studies would be evidence for the operation of a psychological set-point for feelings of personal well-being" (p. 181). Building on the prior work of Headey and Wearing, he suggested that such stability may be due to a 'psychological homeostatic mechanism', a theme elaborated three years later: "It is proposed that life satisfaction is a variable under homeostatic control and with a homeostatic set-point ensuring that populations have, on average, a positive view of their lives" (Cummins, 1998, p. 330).

In 2000, Cummins elaborated his model in which "the psychological processing giving rise to SWB is a highly integrated system that comprises a primary genetic capacity coupled with a secondary buffering system" (p. 137). Among the various psychological devices he proposed to constitute the buffers is adaptation, earlier described by Brickman and Campbell (1971), and more recently developed as 'hedonic adaptation' by Frederick and Loewenstein (1999). While adaptation is certainly one of the processes that operate to maintain SWB homeostasis, the constructs are not equivalent. Rather than a set-point, adaptation implies a range of operation in which a system adjusts to optimise functioning, such as the functional availability of retinal photo-pigments adjusted to light intensity.

Cummins (2000) continues: "The primary system involves two factors of personality that provide a genetically determined range for subjective QOL [Quality Of Life]". This idea, of each person having a genetically-determined and homeostatically managed set-point-range for SWB, represents an important elaboration of the set-point idea. Such a range was earlier conceived in relation to 'psychological functioning' by Williams and Thompson (1993). In the most contemporary statement of this SWB concept, Cummins, Lau and Davern (2012) state: "The aim of homeostasis is to maintain the variable it is managing within a narrow range of values. Thus, SWB must evidence a 'set-point range' which reflects the normal moment-to-moment range in which SWB will be found for each individual. The magnitude of this range may also be an individual difference, with some ranges being more tightly controlled than others. ... Since the magnitude of the set-point range is calculated to be around 10-12\% points (Cummins et al., 2008, Section 3.8.1), the total movement of SWB due to such influences will not be more than a few percentage points on either side of the set point”.

One further elaboration by these authors, in relation to set-points, has involved the construct of Homeostatically Protected Mood (HPMood). Measuring SWB by both GLS and the Personal Wellbeing Index (International Wellbeing Group, 2006), three separate studies have established that responses to the question 'How satisfied are you with your life as a whole?' are highly saturated with mood affect (Blore, Stokes, Mellor, Firth, \& Cummins, 2011; Davern, Cummins, \& Stokes, 2007; Tomyn \& Cummins, 2011). This mood affect is 
dominated by a sense of contentment, flavored with a touch of happiness and arousal. These authors propose that this general, abstract, positive view of the self is generated genetically as a level of positivity, which is an individual difference between people. This proposition is consistent with a recent study of twins showing high levels of heritability in positive affect (Keyes, Myers, \& Kendler, 2010).

The level of HPMood is proposed to represent the SWB set-point for each person, and it is this set-point that the homeostatic system seeks to defend. This defensive system is more elaborately described in the companion paper (Cummins \& Wooden, 2013) as comprising the relatively passive processes of habituation and adaptation, coupled with active cognitive buffers of self-esteem, optimism and perceived control.

In summary, the Theory of Subjective Wellbeing Homeostasis provides a highly testable, theoretical framework for interpreting SWB data. Yet Headey, Muffels and Wagner $(2010,2012)$ proclaim in relation to SWB: "The new challenge for researchers is to develop a theory that accounts for [both stability and] change" (2010, p. 17,922).

\section{Evidence against set-points}

The previously cited line by Lykken and Tellegen (1996), that set-points imply 'trying to be happier is futile' has generated strong debate. Even the more measured statement of Diener and Diener (1996) “that permanently raising SWB above a person's set point is [likely] quite difficult" carries the obvious implication that set-points make it hard to make people happier. Ominously, the acceptance of such statements has been interpreted by Headey et al. (2010) to imply that "neither individual choices nor public policy can make a substantial long-term difference to happiness" (p. 17,922). So, given the unacceptability of such a conclusion, they attempt to fault the evidence for set-points by demonstrating longterm SWB change.

In fact, long-term change in SWB was already well established. For example, Diener and co-workers (Diener, Lucas, \& Scollon, 2006; Fujita \& Diener, 2005; Scollon \& Diener, 2006) have observed that some people experience long-term changes in happiness within both the German Socio-Economic Panel Survey (SOEP) and the Australian panels data set used by Headey and Wearing. Moreover, in a recent comprehensive review of this and other work, (Clark, et al., 2008) conclude that chronic unemployment was linked to a long-term decrease in happiness. Parenthetically, they also state they were unable to find any event that, on average, had a long-term positive effect on happiness. The logical expectation that reemployment should raise the happiness of people who were unemployed is not mentioned.

So against this background, Headey et al. (2010) again demonstrate substantial longterm changes in SWB, but this time make the claim this constitutes: "A direct test of the most widely accepted psychological theory, set-point theory, [which] shows it to be flawed" (Headey et al., 2010, p. 17,922).

So, does the demonstration of long-term change in SWB administer the coup de grace to set-point-theory? Their claim to have done so is based on the demonstration of SWB 
change coupled with an assumption that: "The weakness of set-point theory is that it is purely a theory of stability" (p. 17,922). In evaluating the basis for this conclusion, their finding of changed SWB over time is not in doubt, having been previously found by many researchers, as previously stated. So, their case rests on their assumption that set-point theory can be disproved through the demonstration of SWB change.

We argue that the assumption of immutability in measured SWB is a straw man. Setpoints are hypothetical constructs and any measurements attributed to them can only be made using self-report data. Such data are influenced by many forces, such as momentary affect and depression, which may well be stronger sources of affect than can be provided by a putative set-point. Consequently, any change in SWB cannot be used as evidence for either a changing set-point or the absence of a set-point. Consider the analogy with the set-point for core body temperature $\left(37^{\circ} \mathrm{C}\right)$. Prolonged exposure to a sufficiently hot or cold thermal challenge will cause core body temperature to rise or fall. This does not represent a change in set-point. It is a defeat of homeostasis and, once the source of thermal challenge is removed, body temperature will revert to its set-point.

An alternative theoretical view of SWB set-points is provided within the context of homeostasis theory. In this framework, each set-point represents a level of mood affect (HPMood) which is characteristic of the individual. In order for measured SWB to best approximate the HPMood set-point, the person providing the data should be as free as possible from strong affective influences, either acute or chronic. Our search for set-points is now described, using a methodology guided by expectations based in homeostasis theory. Our single hypothesis is that evidence for the existence of set-points can be demonstrated from longitudinal data.

\section{Method}

The data for this study come from the Household, Income and Labour Dynamics in Australia (HILDA) Survey. This is a broad social and economic, longitudinal survey, initiated and funded by the Australian Government Department of Families, Housing, Community Services and Indigenous Affairs. Surveys have been conducted annually since the first survey in 2001.

The survey began as a random sample of households within defined geographic regions, with samples sizes proportional to population density (for details see Watson \& Wooden, 2002). All members of each selected household, aged 15 years and older, are followed up for each survey. Most interviews are conducted face-to-face, with up to $10 \%$ of interviews being conducted through telephone. Incentives are provided to respondents. In wave 1, a total 13,969 people in 7,682 households were interviewed. Annual re-interview rates are high, rising from $87 \%$ in wave 2 to over $96 \%$ by wave 9 (Watson \& Wooden, 2012).

The data have been drawn from the first 10 consecutive waves of the HILDA Survey, each of which included the question 'All things considered, how satisfied are you with your life?' (General Life Satisfaction: GLS) rated on a $0-10$ response scale. A total of 7,356 respondents provided a full data-set, responding to this question on each occasion. The 74 
respondents who scored 10 for all 10 surveys have been excluded from further analysis. We regard such consistency to reflect either extreme social acquiescence or deliberate misreporting. All results are standardized onto a $0-100$ point scale which, for the current values, has involved shifting the decimal point one space to the right.

\section{Rationale for the analysis}

The aim of our analysis is to identify GLS scores that are most representative of each person over the ten surveys. We then use these scores to estimate set-points and set-pointranges. Our analysis involves an iterative process of data removal, the results of which are shown in Table 1 and Appendix Tables A1 to A5. Our procedure is based on grouping responses into categories with a width of 5-points. This width has been chosen as the smallest width that yields a reliable number of respondents throughout the analysis. The following assumptions and deductions also apply.

Assumption \#1: People who retain homeostatic control over all 10 surveys show a personal mean and standard deviation (SD) that closely reflects their true set-point and setpoint-range, respectively. For such people, the distribution of their individual survey scores will be normally distributed around their personal mean.

Assumption \#2: People who show homeostatic failure in one or more of their 10 responses will exhibit individual survey scores that lie outside their true set-point-range. For such people, the distribution of their individual survey scores will be skewed, with the extent of skew relating to the extent of homeostatic failure.

Deduction \#2.1: The values used to populate the 5-point categories in Table 1 are the average scores of each respondent over the 10 surveys. Thus, a small excursion in one GLS score, on one occasion over the 10 surveys, will make a very small change to the person's mean score, either higher or lower than the true mean of their set-point-range. Such excursions will also slightly increase their personal SD derived from their 10 scores. As these excursions increase, either in magnitude or frequency, the difference between the recorded GLS mean and SD for that person, and their true set-point and set-point-range, will also increase.

Assumption \#3: Within any category in Table 1 there will be a mixture of scores, reflecting various approximations to true set-points and SDs. While some GLS means and SDs will closely approximate that individual's set-point and set-point-range, reflecting consistent homeostatic control, other mean scores and SDs will deviate substantially from an individual's actual set-point and set-point-range. For these latter individuals, the fact of their mean score lying within a particular set-point-range (e.g., 61-65 points) is the result of strong variations from normal occasioned by periods of homeostatic failure. If their deviant scores are removed, retaining only those scores within confidence limits for the person, then their true set-point may be revealed to lie within a different set-point-range (e.g., 71-75 points).

Assumption \#4: People who have a mean score different from their true set-point may or may not be detectable. They may be detectable through an expanded SD if their 
homeostatic defeat was confined to acute episodes. In this circumstance, one or more score excursions beyond the individual's normal range would combine with scores within their normal set-point-range to create enhanced variance. If, however, the homeostatic defeat was chronic, it is possible that a respondent's 10 scores could lie within a narrow range of values far below that respondent's true set-point-range. Such respondents cannot be detected using the current methodology and their inclusion in a category will represent error in the analysis.

Assumption \#5: It would be unusual to have chronic homeostatic defeat over 10 years such that the mean score showed little variation. Moreover, should this occur, the crushing force of negativity that so persistently defeated homeostasis will likely result in a very low mean score, which will lie below the positive categories of interest for the determination of set-point-ranges. Far more likely would be a situation of volatility, such that the respondent's scores would sometimes reflect partial or complete return to their set-pointrange due to acute positive circumstances. These respondents will evidence high SDs, and will be eliminated as described below. In summary, the magnitude of a respondent's SD is likely to be a good indicator of whether their average mean score likely reflects their true setpoint-range.

Assumption \#6: Set-points have a normal distribution reflecting genetic diversity.

Assumption \#7: The mean of this set-point distribution likely approximates the overall data median (this lies in category $75.5-80.0$ in both Table 1 and Table A5). This is because normal homeostatic control is likely to be the most common condition for people in the Australian population, as evidenced by the extraordinary stability of the population SWB mean score, which has varied by only 3.1 percentage points over 26 surveys using the Australian Unity Wellbeing Index (Cummins et al., 2011).

Deduction \#7.1: It then follows that, for those categories close to the overall data median, if a normal range is constructed ( $2 \times \mathrm{SD})$ within any category using raw scores, values that lie either below or above this normal range can be considered outliers, reflecting homeostatic failure. Thus, if the distribution within each category is progressively trimmed to exclude scores more than 2SD from the category mean, the final 2SD value will represent the best estimate of the normal range for that category.

Deduction \#7.2: The category means on either side of the data median will contain a higher proportion of scores identified as outliers. This reflects their higher proportion of scores influenced by homeostatic failure. Thus, they will lose more raw scores through the iterative elimination process.

Deduction \#7.3: Following the final data-elimination iteration, the best approximation of the normal set-point distribution will be revealed as a set of categories with a similar, low-level SD.

In summary, the final mean and normal range for each category can be used as follows: 
(a) The mean of each normal range will approximate the average set-point for the people in that category.

(b) The mean SD of the people with this set-point will approximate their trimmed average response variance across the 10 surveys. Doubling this range $(2 \mathrm{xSD})$ provides a normative range above and below the set-point, with a $95.5 \%$ probability of containing any mean score in this category. This is the approximation to the set-point-range for people in this category. This value will, however, be larger than the true normal set-point-range representing pure homeostatic maintenance, due to the inclusion of means influenced by undetected excursions outside that range.

\section{Results}

The first aim of our analysis is to identify GLS scores that are most representative of each person over the ten surveys. This requires the use of a procedure that trims extreme scores and smooths data through the use of confidence intervals. The procedure is as follows.

Each respondent provided 10 GLS raw scores. These scores have been used to generate a within-person mean. These means have then been used to place each respondent into a category in Table 1. Each of the GLS category ranges is, with one exception, 5 points. The 18 point range representing the $17-45$ point category has been created to give a workable number of respondents. Thus, in order for a respondent to fall within a category, their average score over the 10 surveys must fall into that category range. So for example, in the 96-100 category range, a total of 309 people, comprising $4.2 \%$ of the total 7,356 respondents, had a mean score within this range. Note that, due to the exclusion of respondents who achieved a maximum score for each survey, no respondent in this table had a mean score of 100. However, other respondents contributed valid raw scores of 100, so this upper limit to the category is acceptable.

Beyond the use of mean scores to place respondents into categories, all of the results in Table 1 are derived from raw scores. Thus, a respondent with a mean score that placed them into the 96-100 point range would donate their 10 raw scores to the $96-100$ point category. The analytic process that follows has the aim of reducing the population of raw scores such that all remaining lie within the $95.5 \%$ confidence limits of each category. This will involve an iterative process of data removal. The first iteration is shown in Table 1 and the explanation of the columns in this table is as follows:

Column 2: The initial number of raw scores (number of respondents $x$ 10) and the percentage these scores comprise of the total sample $(73,560)$ at this iteration.

Column 3: The category mean.

Column 4: The category SD based on raw scores.

Column 5: The lower 95.5\% confidence limit (category mean minus x2SD). 
Column 6: The upper 95.5\% confidence limit (category mean plus x2SD).

Column 7: The number of scores below the lower confidence limit.

Column 8: The number of scores above the upper confidence limit.

Column 9: The number of scores excluded in this iteration (the total number falling outside the confidence limits).

Column 10: Percentage of scores excluded as a proportion of the initial number of raw scores in the category at this iteration.

Column 11: The residual number of raw scores carried into the next iteration.

Table 1:

GLS raw scores, confidence limits and the statistics of the first iteration for score elimination

\begin{tabular}{|c|c|c|c|c|c|c|c|c|c|c|}
\hline $\begin{array}{l}\text { 5-point } \\
\text { GLS } \\
\text { categories }\end{array}$ & $\begin{array}{l}\mathbf{N} \text { in } \\
\text { category } \\
\text { (\% of total } \\
\text { sample) }\end{array}$ & $\begin{array}{l}\text { Category } \\
\text { raw } \\
\text { score } \\
\text { Mean }\end{array}$ & $\begin{array}{l}\text { Category } \\
\text { raw } \\
\text { score } \\
\text { SD }\end{array}$ & $\begin{array}{l}\text { Category } \\
\text { mean } \\
\text { minus } \\
\text { x2SD }\end{array}$ & $\begin{array}{l}\text { Category } \\
\text { mean } \\
\text { plus } \\
\text { X2SD }\end{array}$ & $\begin{array}{l}\text { Scores } \\
\text { below } \\
\text { lower limit } \\
(\mathrm{N})\end{array}$ & $\begin{array}{l}\text { Scores } \\
\text { above } \\
\text { upper limit } \\
\text { (N) }\end{array}$ & $\begin{array}{l}\text { Scores } \\
\text { excluded } \\
\text { (N) }\end{array}$ & $\begin{array}{l}\text { Scores } \\
\text { excluded } \\
(\%)\end{array}$ & $\begin{array}{l}\text { Scores } \\
\text { remaining } \\
\text { (N) }\end{array}$ \\
\hline $17.0-45.0$ & $\begin{array}{l}650 \\
(0.88)\end{array}$ & 37.20 & 17.94 & 1.33 & 73.07 & 42 & 16 & 58 & 8.92 & 592 \\
\hline $45.5-50.0$ & $\begin{array}{l}630 \\
(0.86)\end{array}$ & 48.17 & 16.19 & 15.79 & 80.56 & 17 & 10 & 27 & 4.29 & 603 \\
\hline $51.0-55.0$ & $\begin{array}{l}\mathbf{1 , 2 9 0} \\
(1.75)\end{array}$ & 53.12 & 15.96 & 21.19 & 85.04 & 64 & 25 & 89 & 6.90 & 1,201 \\
\hline $55.5-60.0$ & $\begin{array}{l}1,720 \\
(2.34)\end{array}$ & 58.11 & 15.25 & 27.61 & 88.61 & 53 & 46 & 99 & 5.76 & 1,621 \\
\hline $61.0-65.0$ & $\begin{array}{l}3,150 \\
(4.28)\end{array}$ & 63.27 & 12.88 & 37.50 & 89.03 & 92 & 88 & 180 & 5.71 & 2,970 \\
\hline $65.5-70.0$ & $\begin{array}{l}6,270 \\
(8.52)\end{array}$ & 68.24 & 11.37 & 45.50 & 90.98 & 206 & 76 & 282 & 4.50 & 5,988 \\
\hline $71.0-75.0$ & $\begin{array}{l}\mathbf{1 0 , 2 9 0} \\
(13.99)\end{array}$ & 73.19 & 9.53 & 54.13 & 92.25 & 500 & 158 & 658 & 6.39 & 9,632 \\
\hline $75.5-80.0$ & $\begin{array}{l}\mathbf{1 4 , 2 6 0} \\
(19.39)\end{array}$ & 78.11 & 8.36 & 61.39 & 94.83 & 741 & 366 & 1,107 & 7.76 & 13,153 \\
\hline $81.0-85.0$ & $\begin{array}{l}14,770 \\
(20.08)\end{array}$ & 82.90 & 8.29 & 66.33 & 99.47 & 354 & 1,035 & 1,389 & 9.40 & 13,381 \\
\hline $85.5-90.0$ & $\begin{array}{l}11,220 \\
(15.25)\end{array}$ & 87.85 & 7.76 & 72.33 & 103.38 & 468 & 0 & 468 & 4.17 & 10,752 \\
\hline $91.0-95.0$ & $\begin{array}{l}6,220 \\
(8.46)\end{array}$ & 92.76 & 7.49 & 77.79 & 107.74 & 106 & 0 & 106 & 1.70 & 6,114 \\
\hline $95.5-100$ & $\begin{array}{l}3,090 \\
(4.2) \\
\end{array}$ & 97.41 & 5.31 & 86.80 & 108.03 & 124 & 0 & 124 & 4.01 & 2,966 \\
\hline Total & 73,560 & & & & & 2,767 & 1,820 & 4,587 & & 68,973 \\
\hline
\end{tabular}

From Table 1, the distribution of GLS raw scores shows the usual negative skew, with a median between 75.5 and 85 points. Notable is the relatively small proportion of respondents (3.49\%) lying below 55 points. It has been argued elsewhere (Cummins, 2010) that such low values correspond with homeostatic defeat. 
At the end of iteration 1 there are a total of 68,973 raw scores left in the sample. The process of the second iteration repeats that of the first. For those respondents who had scores eliminated in the previous iteration, their mean score will change in iteration 2. Such respondents may therefore be reclassified into a different category. Consequently the ' $\mathrm{N}$ in category' (column 2) may not be the same for each category as the number in the last column in Table 1. However, the total number of remaining scores is the same $(68,973)$. The tables showing the remaining iterations 2 to 6 are provided in Appendix Tables A1 to A5. After 5 iterations all values remaining in all categories fall within the confidence limits for each category.

The final step in our process of data elimination is to ensure respondents have a sufficient number of scores remaining to reliably support a determination of set-points. To this stage, none of the initial 7,356 respondents had been excluded. A distribution table showed that 61 people $(0.82 \%)$ were left with 3 scores or less. An observational analysis of these remaining scores, within each person, indicated considerable diversity. This high variation reduced considerable for people with 4 scores remaining $(\mathrm{N}=114,1.55 \%)$. Thus the decision was made to restrict the final sample to the 7,295 people with 4 scores or more after the fifth iteration.

\section{Testing the predictions following data removal}

Deduction \#7.2: The category means on either side of the data median will contain a higher proportion of scores identified as outliers. This reflects their higher proportion of scores influenced by homeostatic failure. Thus, they will lose more raw scores through the iterative elimination process.

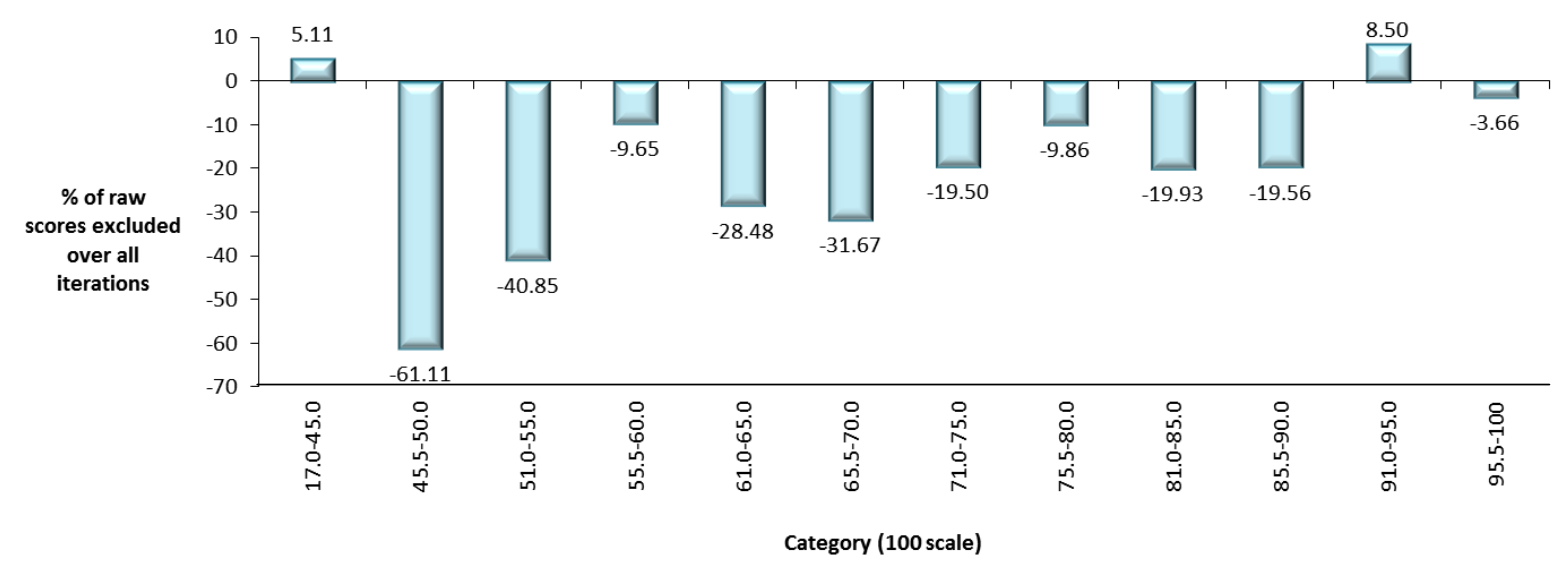

Figure 1: The percentage change of raw scores within categories from the $1^{\text {st }}$ to the $5^{\text {th }}$ iteration

The pattern in Figure 1 centres on the $75.5-80.0$ point category, which contains the data median score. As predicted, the categories on either side have lost substantially more, over double the proportion of their scores, during the process of data elimination. This applies 
over the range of 65.5-70.0 to 85.5-90.0. Both above and below this bracket of categories other forces cause different patterns to be evident.

Above this bracket both categories show a different pattern. The 91.0-95.0 shows an $8.5 \%$ increase in raw scores. This indicates that, with the removal of outliers, more respondent's mean scores have entered this category than have left. This category started with 6,220 scores (8.46\% of the total: Table 1) and ended with 6,798 scores $(11.05 \%$ of the total remaining: Table 3 ). It seems most likely that this category has gained its $2.59 \%$ from the top 95.5-100 category, which diminished by $3.66 \%$. This $91.0-95.0$ category is very interesting, showing that around $11 \%$ of the sample has generally maintained very high GLS scores throughout the 10 surveys.

Below the 65.5-70.0 category, the proportion of eliminated scores falls to a nadir at 55.5-60.0, and then rises again up to 45.5-50.0. All of these categories indicate the elimination of low outliers from respondents with higher set-points. The total number of responses at 50 points or less, after the final iteration, is 930 (Table A6) or $1.51 \%$ of the remaining sample. This is a dramatic demonstration of the normal positivity of GLS.

Deduction \#7.3: Following the final data-elimination iteration, the best approximation of the normal set-point distribution will be revealed as a set of categories with a consistent, low SD.

In Table 2, two forms of average variance have been calculated for each category. Both are based on within-person calculations, rather than the raw-score calculations in Table 1. The first is the average SD of the respondents within each category ('Mean of SDs in category'). The second is the SD of the SDs within each category ('SD of SDs in category'). Both statistics provide information on the spread of GLS scores for respondents with similar mean scores. 
Table 2:

Average within-person variance for each category, before the first iteration, and after the fifth

\begin{tabular}{l|ll|ll}
\multirow{2}{*}{$\begin{array}{l}\text { 5-point GLS } \\
\text { categories }\end{array}$} & $\begin{array}{l}\text { Before the first iteration } \\
\text { Mean of SDs in }\end{array}$ & $\begin{array}{l}\text { SD of } \\
\text { SDetegory }\end{array}$ & After the fifth iteration & \\
\hline $17-45$ & 17.93 & 6.09 & Mean SD of category & SD of SD's in category \\
$46-50$ & 16.19 & 7.13 & 11.30 & 2.99 \\
$51-55$ & 15.96 & 6.52 & 5.72 & 2.52 \\
$56-60$ & 15.24 & 5.97 & 8.66 & 2.41 \\
$61-65$ & 12.88 & 5.25 & 10.91 & 2.54 \\
$66-70$ & 11.36 & 5.53 & 9.32 & 2.52 \\
$71-75$ & 9.52 & 4.83 & 6.40 & 1.97 \\
$76-80$ & 8.35 & 4.46 & 5.04 & 0.47 \\
$81-85$ & 8.28 & 3.77 & 4.46 & 1.17 \\
$86-90$ & 7.76 & 3.62 & 4.84 & 0.62 \\
$91-95$ & 7.48 & 2.63 & 4.59 & 1.08 \\
$96-100$ & 5.30 & 1.82 & 6.91 & 1.74 \\
& & & 0.00 & 0.00
\end{tabular}

Before the first iteration, both measures of variance rise in a linear fashion as the category mean falls. This is expected due to a combination of ceiling effects among the high categories and an increasing tendency for response instability and negative homeostatic defeat among the low scoring categories.

Following the $5^{\text {th }}$ iteration, the variance within the categories has lost its regular relationship with the mean. The most dramatic change is for the 96-100 point category, which has zero variance because all 2,977 scores are 100 (Table A5).

In terms of the other categories, the presence of set-points should be signalled by the pattern of within-person variance as it relates to the GLS mean score of each individual. The crucial assumption for the deductions that follow is that, under conditions of effective homeostatic maintenance, the within-person variance should be unrelated to the level of GLS. This is because there is no a priori reason to expect that the magnitude of set-point-ranges would differ within a genetically-determined normal range of set-points. However, both above and below this range of effective homeostasis, the within-person variance does relate to the category mean score. For scores above this range, within-person variance will be reduced by ceiling effects. Below this homeostatic range, within-person variance will be increased by the more persistent inclusion of people who are oscillating in and out of homeostatic failure. Due to their higher frequency, such scores are more likely to look like they belong to an expanded normal range and so are less likely to be eliminated by the fifth iteration. In summary, a plateau of within-person variance should be evident in the $5^{\text {th }}$ iteration, over a range of GLS categories. This range should signal the spread of set-points being effectively defended by homeostatic control. 
The upper-line results shown in Figure 2 are taken from the 2nd column of Table 2. This shows the within-person mean of standard deviations for GLS, for each category, before data elimination. There is a close to linear decrease in the category within-person SDs as the group means increase from 45.0 points to 95 points. The minimum number of within-person estimates of SD is 63 (Category 46-50 points) and the maximum is 1,477 (Category 81-85 points).

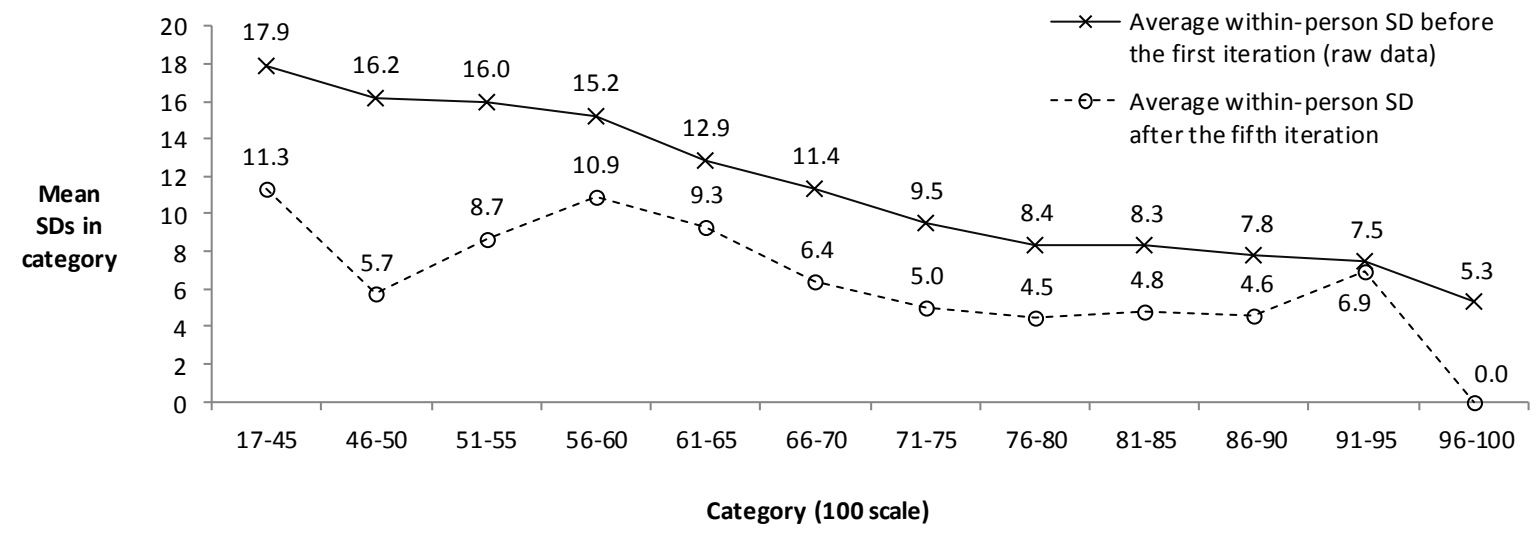

Figure 2: 5-point GLS categories vs Standard Deviations

The final results from the iterative data elimination process are shown by the lower line in Figure 2. This shows that over the 19 point range, from 71 to 90 points, the category within-person SD range is stable, varying by just 0.50 points (from 4.5 to 5.0 ).

We propose that this stable value of 4 to 5 points, represents a reasonable estimate of the normal variation of the set-point-range within each GLS category. When doubled (2xSD), this indicates that there is a $95.5 \%$ probability of locating each resting GLS value within a 9 to 10 percentage-point range around its mean value.

The final result to be presented concerns Assumption \#6: Set-points have a normal distribution reflecting genetic diversity. Applying the set-point distribution to the final sample shown in Appendix Table A6 yields the following proportions: $\langle 71=15.90 \%, 71-90=$ $68.22 \%,>90=15.88 \%$. Within the set-point-range the proportions are: $71-75=13.46 \%, 76-$ $80=20.88 \%, 81-85=19.21 \%, 86-90=14.66 \%$. We conclude that this distribution is consistent with the assumption.

\section{Discussion}

Our major finding is that set-points for General Life Satisfaction (GLS) appears to have been demonstrated between the levels of 71 and 90 points. We estimate they have a normal operating range (set-point-range) of around 18 to 20 points. This demonstration of set-points is counter to the determined prognostications from various senior researchers, as described in the introduction. Two reasons for this misconception can be identified. One is an 
overly simplistic view of adaptation and the other is misunderstanding of homeostatic processes.

Despite statements that adaptation to life events occurs within some specific time frame (e.g. Headey, et al., 2010; McGue, et al., 1993), in reality the evidence on the time taken for SWB adaptation is very mixed. Some reports evidence little or only partial adaptation to events such as marital divorce, the onset of disability and unemployment (e.g. Lucas, 2005, 2007; Lucas, Clark, Georgellis, \& Diener, 2004; Oswald \& Powdthavee, 2008). In contrast, other research involving much longer lists of events, report complete adaptation to many (even most) events, but not all (e.g. Clark, et al., 2008; Frijters, Johnston, \& Shields, 2011). The mixed nature of these findings should not be surprising.

There can be no single, universal time-span for adaptation. The time taken to adapt will, at the simplest level, depend on the balance of two forces. One is the strength and persistence of the psychological challenge provided by the event, and second is the material and psychological resources of each person to recover homeostatic control. Clearly, therefore, recovery time through adaptation is highly idiosyncratic and, indeed, may never occur if the balance of challenge versus resources remains strongly unfavourable.

The second source of misunderstanding involves the nexus between what is measured and the fixity, or otherwise, of underlying neuro-psychological processes. The view of fixity was first introduced by Headey and Wearing $(1989,1992)$, and reiterated by Headey (2010). They dismiss the proposition that the stability in SWB depends on stable personality traits or set-points, because this would mean that people's level of SWB "would remain virtually unchanged over their entire lifetimes" (1992, p. 145). In the context of SWB homeostasis, this is an important misconception. There are two reasons. The first is a misunderstanding of homeostasis as a construct.

The original conception of homeostasis (Cannon, 1932) refers to steady states of the body actively maintained by corrective physiological and behavioural mechanisms. An elaboration is offered by Keesey and Powley (1986) who suggest the term homeostasis specifically connotes active defence. That is, the process of dynamic compensation for changes in some state or level typically generates a degree of stability in the regulated factor. They also agree with Cannon (1932) that the term homeostasis does not imply fixity. Rather, homeostatically controlled body states may vary within tolerated limits, where such variation may be caused by either disturbances or necessary regulatory adjustments. Keesey and Powley (1986) also note that Cannon (1932) applied the term homeostasis to behavior as well as to physiological regulation. Regarding homeostatically defended set-points for psychological functioning, Williams and Thompson (1993) note: "Surrounding this set-point, it could easily be imagined that a bandwidth or range of functioning exists. The individual would be flexible (psychologically or personality-wise) around this set-point within the bandwidth" (p. 51).

In sum, there is nothing within the notion of homeostatic set-points that implies the variable under consideration will remain constant. Even within normal functioning there is 
variation within a 'bandwidth'. However, such normal variations should be contained to a range that does not challenge normal functioning of the variable in question. Far greater variation can be imposed by chronic homeostatic failure.

This introduces the second misunderstanding of the relationship between reported SWB and set-points. To use the same analogy as presented in the introduction, hypothermia is diagnostic of thermal homeostatic failure, not of a changed set-point. So it is with SWB homeostasis. If the degree of challenge to SWB homeostasis is too strong or prolonged, the normal buffering and compensatory processes will be unable to defend the set-point level of SWB. When this occurs, the overt negativity or positivity of the challenging agent will dominate conscious awareness of affect, and reported levels of SWB will lie outside the setpoint-range. In this conception, the actual set-point remains unaltered, and normal levels of SWB can again be experienced if the strength of challenge is reduced by either the application of resources or through adaptation.

In the light of these clarifications, our finding of set-points for GLS is unsurprising. However, our calculated value for the set-point-range is almost certainly an over-estimate.

\section{Limitations to the empirical estimates}

In accounting for the within-person variance that constitutes our estimate of each setpoint-range, it is proposed that there are four potential contributory sources as follows:

1. Deviations around the individual's set-point that lie within their valid set-pointrange. This is the variance being sought and is included within each set-pointrange calculation. Unfortunately, this variance can only be identified by default, through the removal of non-valid variance. Thus, since the identification of nonvalid variance is limited by the techniques we have used, the valid set-pointranges are certainly smaller than our estimate.

2. Deviations from the individual's set-point that lie outside their set-point-range due to short-term emotional responses. These may cause either a small or large degree of skew in the score distribution, depending on both the degree of their excursion from the set-point-range and also the frequency of their occurrence within the 10 responses for each person. Such deviations will also exert a correspondingly small or large discrepancy between the measured mean and valid set-point. On average, however, it has been estimated that short-term emotional states are likely to exert a small influence on SWB (Deinzer et al., 1995; Eid \& Diener, 2004) when measured under normal survey conditions.

3. Deviations from the individual's set-point that lie outside their set-point-range due to long term homeostatic compromise or defeat. The influence of such values is hard to predict. Most likely they will represent an exaggerated version of (2) but it is also possible that, if the level of homeostatic defeat is persistent and strong, the scores could form a coherent group some distance below their set-point-range. 
This seems unlikely over the span of 10 years but, if it did occur, it would give the false impression of a very low set-point.

4. Set-points as individual differences within the width of the category. Since the category width for our analysis is 5 points, this clearly adds variance to the between-person variance. However, it should not influence the within-person variance assuming that the width of set-point-ranges are constant within the category range that corresponds to effective homeostatic control.

In summary, the iterative process of data removal has reduced, but not removed, the influences of (2) and (3) only. Thus, we have undoubtedly overestimated the width of the setpoint-range.

\section{Conclusion}

Our determination of set-points for GLS allows a new perspective onto various influential conclusions reached by other researchers. First, the Lykken and Tellegen (1996) conclusion that set-points imply 'trying to be happier is futile' may or may not be correct. It is very likely to be correct when applied to a group that: (a) contains a normal distribution of set-points (between 70 and 90 points); and (b) has a mean score that lies above the mid-point of the set-point distribution ( 80 points). Under these conditions both measurement and homeostatic ceiling effects will start to be evident. The higher the group mean score rises above 80 points the more homeostatic pressure will be generated to return SWB to each setpoint.

This same logic involving homeostatic pressure will apply to SWB means that lie below 80 points, as long as the level of SWB remains under homeostatic control. However, when the force of challenge defeats homeostasis, the level of SWB is being controlled by the challenging agent, and can drop to very low levels. Under these conditions, the Lykken and Tellegen (1996) conclusion is incorrect. The addition of appropriate resources (see Cummins, 2010) to such groups has the potential to raise their SWB up to the point that their SWB returns to lie within the set-point-ranges and within homeostatic control.

Our second conclusion rebuts the interpretation of set point theory as set forth by (Headey, et al., 2010) that "neither individual choices nor public policy can make a substantial long-term difference to happiness" (p. 17,922). Such a misinterpretation of set point theory is based on the idea that low SWB implies a low set-point, while in fact it implies homeostatic defeat. According to the evidence and logic applied in this paper, when additional financial resources, for example, are directed to groups evidencing homeostatic failure, their SWB will rise. Moreover, if the necessary levels of the resource are maintained, so too will the elevated levels of SWB, as such people are returned to settle into their homeostatically defended set-point-range. 


\section{APPENDIX}

Table A1: Beginning and Ending Status of Iteration 2

\begin{tabular}{|c|c|c|c|c|c|c|c|c|}
\hline $\begin{array}{l}\text { Category } \\
(100 \\
\text { scale })\end{array}$ & $\begin{array}{l}\text { Number of } \\
\text { Scores in } \\
\text { Category }\end{array}$ & $\begin{array}{l}\text { Category } \\
\text { Mean }\end{array}$ & $\begin{array}{l}\text { Category } \\
\text { SD }\end{array}$ & $\begin{array}{l}\text { Category } \\
\text { mean minus } \\
\text { x2SD }\end{array}$ & $\begin{array}{l}\text { Category } \\
\text { mean } \\
\text { plus x2SD }\end{array}$ & $\begin{array}{l}\text { Number of } \\
\text { Scores } \\
\text { Excluded }\end{array}$ & $\begin{array}{l}\% \text { of } \\
\text { Scores } \\
\text { Excluded }\end{array}$ & $\begin{array}{l}\text { Number of } \\
\text { Scores } \\
\text { Left }\end{array}$ \\
\hline $17.0-45.0$ & 592 & 38.24 & 15.10 & 8.04 & 68.45 & 34 & 5.74 & 558 \\
\hline $45.5-50.0$ & 635 & 48.22 & 13.74 & 20.73 & 75.71 & 53 & 8.35 & 582 \\
\hline $51.0-55.0$ & 1018 & 53.33 & 12.27 & 28.79 & 77.87 & 48 & 4.72 & 970 \\
\hline $55.5-60.0$ & 1677 & 58.18 & 12.48 & 33.22 & 83.13 & 60 & 3.58 & 1617 \\
\hline $61.0-65.0$ & 2669 & 63.26 & 10.57 & 42.13 & 84.40 & 107 & 4.01 & 2562 \\
\hline $65.5-70.0$ & 5547 & 68.32 & 9.07 & 50.18 & 86.46 & 642 & 11.57 & 4905 \\
\hline $71.0-75.0$ & 8466 & 73.30 & 7.17 & 58.96 & 87.64 & 376 & 4.44 & 8090 \\
\hline $75.5-80.0$ & 14837 & 78.26 & 6.23 & 65.79 & 90.72 & 151 & 1.02 & 14686 \\
\hline $81.0-85.0$ & 13101 & 82.57 & 6.10 & 70.37 & 94.77 & 1161 & 8.86 & 11940 \\
\hline $85.5-90.0$ & 9970 & 88.10 & 6.17 & 75.77 & 100.43 & 11 & 0.11 & 9959 \\
\hline $91.0-95.0$ & 6798 & 92.77 & 6.91 & 78.94 & 106.60 & 0 & 0.00 & 6798 \\
\hline $95.5-100$ & 3663 & 98.00 & 3.96 & 90.08 & 105.93 & 686 & 18.73 & 2977 \\
\hline Total & 68973 & & & & & 3329 & 4.83 & 65644 \\
\hline
\end{tabular}

Table A2: Beginning and Ending Status of Iteration 3

\begin{tabular}{|c|c|c|c|c|c|c|c|c|}
\hline $\begin{array}{l}\text { Category } \\
(100 \\
\text { scale })\end{array}$ & $\begin{array}{l}\text { Number of } \\
\text { Scores in } \\
\text { Category }\end{array}$ & $\begin{array}{l}\text { Category } \\
\text { Mean }\end{array}$ & $\begin{array}{l}\text { Category } \\
\text { SD }\end{array}$ & $\begin{array}{l}\text { Category } \\
\text { mean minus } \\
\text { x2SD }\end{array}$ & $\begin{array}{l}\text { Category } \\
\text { mean } \\
\text { plus x2SD }\end{array}$ & $\begin{array}{l}\text { Number of } \\
\text { Scores } \\
\text { Excluded }\end{array}$ & $\begin{array}{l}\% \text { of } \\
\text { Scores } \\
\text { Excluded }\end{array}$ & $\begin{array}{l}\text { Number of } \\
\text { Scores } \\
\text { Left }\end{array}$ \\
\hline $17.0-45.0$ & 630 & 37.14 & 13.27 & 10.59 & 63.69 & 57 & 9.05 & 573 \\
\hline $45.5-50.0$ & 606 & 48.43 & 10.80 & 26.84 & 70.02 & 0 & 0.00 & 606 \\
\hline $51.0-55.0$ & 869 & 52.89 & 10.80 & 31.29 & 74.48 & 51 & 5.87 & 818 \\
\hline $55.5-60.0$ & 1365 & 58.41 & 11.11 & 36.19 & 80.63 & 0 & 0.00 & 1365 \\
\hline $61.0-65.0$ & 2304 & 63.43 & 9.55 & 44.34 & 82.52 & 16 & 0.69 & 2288 \\
\hline $65.5-70.0$ & 4502 & 68.61 & 6.88 & 54.84 & 82.38 & 85 & 1.89 & 4417 \\
\hline $71.0-75.0$ & 8851 & 72.88 & 6.35 & 60.17 & 85.59 & 836 & 9.45 & 8015 \\
\hline $75.5-80.0$ & 14609 & 78.37 & 5.98 & 66.41 & 90.33 & 2 & 0.01 & 14607 \\
\hline $81.0-85.0$ & 10200 & 83.26 & 4.84 & 73.58 & 92.93 & 33 & 0.32 & 10167 \\
\hline $85.5-90.0$ & 11933 & 87.83 & 5.95 & 75.93 & 99.74 & 1195 & 10.01 & 10738 \\
\hline $91.0-95.0$ & 6798 & 92.77 & 6.91 & 78.94 & 100.00 & 0 & 0.00 & 6798 \\
\hline $95.5-100$ & 2977 & 100.00 & 0.00 & 100.00 & 106.60 & 0 & 0.00 & 2977 \\
\hline Total & 65644 & & & & & 2275 & 3.47 & 63369 \\
\hline
\end{tabular}


Table A3: Beginning and Ending Status of Iteration 4

\begin{tabular}{|c|c|c|c|c|c|c|c|c|}
\hline $\begin{array}{l}\text { Category } \\
\text { (100 scale) }\end{array}$ & $\begin{array}{l}\text { Number of } \\
\text { Scores in } \\
\text { Category }\end{array}$ & $\begin{array}{l}\text { Category } \\
\text { Mean }\end{array}$ & $\begin{array}{l}\text { Category } \\
\text { SD }\end{array}$ & $\begin{array}{l}\text { Category } \\
\text { mean minus } \\
\mathrm{x} 2 \mathrm{SD}\end{array}$ & $\begin{array}{l}\text { Category } \\
\text { mean } \\
\text { plus x2SD }\end{array}$ & $\begin{array}{l}\text { Number of } \\
\text { Scores } \\
\text { Excluded }\end{array}$ & $\begin{array}{l}\% \text { of } \\
\text { Scores } \\
\text { Excluded }\end{array}$ & $\begin{array}{l}\text { Number } \\
\text { of Scores } \\
\text { Left }\end{array}$ \\
\hline $17.0-45.0$ & 532 & 38.72 & 11.65 & 15.41 & 62.03 & 0 & 0.00 & 532 \\
\hline $45.5-50.0$ & 639 & 48.40 & 10.71 & 26.98 & 69.83 & 48 & 7.51 & 591 \\
\hline $51.0-55.0$ & 621 & 53.20 & 9.30 & 34.61 & 71.80 & 1 & 0.16 & 620 \\
\hline $55.5-60.0$ & 1554 & 58.27 & 10.91 & 36.44 & 80.10 & 0 & 0.00 & 1554 \\
\hline $61.0-65.0$ & 2253 & 63.48 & 9.32 & 44.83 & 82.13 & 0 & 0.00 & 2253 \\
\hline $65.5-70.0$ & 4281 & 68.80 & 6.51 & 55.78 & 81.82 & 9 & 0.21 & 4272 \\
\hline $71.0-75.0$ & 6508 & 73.57 & 5.02 & 63.52 & 83.61 & 28 & 0.43 & 6480 \\
\hline $75.5-80.0$ & 16355 & 78.19 & 5.85 & 66.49 & 89.89 & 1683 & 10.29 & 14672 \\
\hline $81.0-85.0$ & 11826 & 83.37 & 4.84 & 73.70 & 93.05 & 0 & 0.00 & 11826 \\
\hline $85.5-90.0$ & 9025 & 87.01 & 4.59 & 77.83 & 96.19 & 0 & 0.00 & 9025 \\
\hline $91.0-95.0$ & 6798 & 92.77 & 6.91 & 78.94 & 106.60 & 0 & 0.00 & 6798 \\
\hline $95.5-100$ & 2977 & 100.00 & 0.00 & 100.00 & 100.00 & 0 & 0.00 & 2977 \\
\hline Total & 63369 & & & & & 1769 & 2.79 & 61600 \\
\hline
\end{tabular}

Table A4: Beginning and Ending Status of Iteration 5

\begin{tabular}{l|llllllll}
$\begin{array}{l}\text { Category } \\
\text { (100 } \\
\text { scale) }\end{array}$ & $\begin{array}{l}\text { Number of } \\
\text { Scores in } \\
\text { Category }\end{array}$ & $\begin{array}{l}\text { Category } \\
\text { Mean }\end{array}$ & $\begin{array}{l}\text { Category } \\
\text { SD }\end{array}$ & $\begin{array}{l}\text { Category } \\
\text { mean minus } \\
\text { x2SD }\end{array}$ & $\begin{array}{l}\text { Category } \\
\text { mean } \\
\text { plus x2SD }\end{array}$ & $\begin{array}{l}\text { Number of } \\
\text { Scores } \\
\text { Excluded }\end{array}$ & $\begin{array}{l}\text { \% of } \\
\text { Scores } \\
\text { Excluded }\end{array}$ & $\begin{array}{l}\text { Number of } \\
\text { Scores } \\
\text { Left }\end{array}$ \\
\hline $\begin{array}{l}17.0-45.0 \\
45.5-50.0\end{array}$ & $\begin{array}{l}685 \\
438\end{array}$ & 49.78 & 11.30 & 17.18 & 62.38 & 0 & 0.00 & 685 \\
$51.0-55.0$ & 620 & 53.24 & 9.26 & 34.72 & 71.77 & 0 & 11.42 & 388 \\
$55.5-60.0$ & 1554 & 58.27 & 10.91 & 36.44 & 80.10 & 0 & 0.00 & 620 \\
$61.0-65.0$ & 2253 & 63.48 & 9.32 & 44.83 & 82.13 & 0 & 0.00 & 1554 \\
$65.5-70.0$ & 4284 & 68.82 & 6.40 & 56.01 & 81.62 & 0 & 0.00 & 2253 \\
$71.0-75.0$ & 8288 & 73.75 & 5.04 & 63.67 & 83.83 & 2 & 0.00 & 4284 \\
$75.5-80.0$ & 12852 & 77.23 & 4.46 & 68.31 & 86.14 & 1 & 0.02 & 8286 \\
$81.0-85.0$ & 11826 & 83.37 & 4.84 & 73.70 & 93.05 & 0 & 0.01 & 12851 \\
$85.5-90.0$ & 9025 & 87.01 & 4.59 & 77.83 & 96.19 & 0 & 0.00 & 11826 \\
$91.0-95.0$ & 6798 & 92.77 & 6.91 & 78.94 & 106.60 & 0 & 0.00 & 9025 \\
$95.5-100$ & 2977 & 100.00 & 0.00 & 100.00 & 100.00 & 0 & 0.00 & 6798 \\
\hline Total & 61600 & & & & & 53 & 0.00 & 2977 \\
\hline
\end{tabular}


Table A5: Beginning and Ending Status of Iteration 6

\begin{tabular}{l|llllllll}
$\begin{array}{l}\text { Category } \\
\left(\begin{array}{l}\mathbf{1 0 0} \\
\text { scale) }\end{array}\right.\end{array}$ & $\begin{array}{l}\text { Number of } \\
\text { Scores in } \\
\text { Category }\end{array}$ & $\begin{array}{l}\text { Category } \\
\text { Mean }\end{array}$ & $\begin{array}{l}\text { Category } \\
\text { SD }\end{array}$ & $\begin{array}{l}\text { Category } \\
\text { mean minus } \\
\text { x2SD }\end{array}$ & $\begin{array}{l}\text { Category } \\
\text { mean } \\
\text { plus x2SD }\end{array}$ & $\begin{array}{l}\text { Number of } \\
\text { Scores } \\
\text { Excluded }\end{array}$ & $\begin{array}{l}\text { \% of } \\
\text { Scores } \\
\text { Excluded }\end{array}$ & $\begin{array}{l}\text { Number of } \\
\text { Scores } \\
\text { Left }\end{array}$ \\
\hline $\begin{array}{l}17.0-45.0 \\
685\end{array}$ & 39.78 & 11.30 & 17.18 & 62.38 & 0 & 0.00 & 685 \\
$45.5-50.0$ & 245 & 48.94 & 5.72 & 37.51 & 60.37 & 0 & 0.00 & 245 \\
$51.0-55.0$ & 763 & 53.00 & 8.66 & 35.67 & 70.33 & 0 & 0.00 & 763 \\
$55.5-60.0$ & 1554 & 58.27 & 10.91 & 36.44 & 80.10 & 0 & 0.00 & 1554 \\
$61.0-65.0$ & 2253 & 63.48 & 9.32 & 44.83 & 82.13 & 0 & 0.00 & 2253 \\
$65.5-70.0$ & 4284 & 68.82 & 6.40 & 56.01 & 81.62 & 0 & 0.00 & 4284 \\
$71.0-75.0$ & 8283 & 73.75 & 5.04 & 63.68 & 83.82 & 0 & 0.00 & 8283 \\
$75.5-80.0$ & 12854 & 77.23 & 4.46 & 68.32 & 86.14 & 0 & 0.00 & 12854 \\
$81.0-85.0$ & 11826 & 83.37 & 4.84 & 73.70 & 93.05 & 0 & 0.00 & 11826 \\
$85.5-90.0$ & 9025 & 87.01 & 4.59 & 77.83 & 96.19 & 0 & 0.00 & 9025 \\
$91.0-95.0$ & 6798 & 92.77 & 6.91 & 78.94 & 106.60 & 0 & 0.00 & 6798 \\
$95.5-100$ & 2977 & 100.00 & 0.00 & 100.00 & 100.00 & 0 & 0.00 & 2977 \\
\hline Total & 61547 & & & & & & & 61547
\end{tabular}

Table A6: Summary of score distribution changes between categories through the five iterations

\begin{tabular}{lllllll}
$\begin{array}{l}\text { 5-point GLS } \\
\text { Categories }\end{array}$ & $\begin{array}{l}\text { N before first } \\
\text { iteration }\end{array}$ & $\begin{array}{l}\text { \% of total } \\
\text { before first } \\
\text { iteration }\end{array}$ & $\begin{array}{l}\text { N after last } \\
\text { iteration }\end{array}$ & $\begin{array}{l}\text { \% of total after } \\
\text { last iteration }\end{array}$ & $\begin{array}{l}\text { N change first } \\
\text { to last }\end{array}$ & $\begin{array}{l}\text { \% of total } \\
\text { change first to } \\
\text { last }\end{array}$ \\
\hline $\begin{array}{l}17.0-45.0 \\
\mathbf{6 5 0}\end{array}$ & 0.88 & 685 & 1.11 & +35 & +5.11 \\
$45.5-50.0$ & $\mathbf{6 3 0}$ & 0.86 & 245 & 0.40 & -385 & -61.11 \\
$51.0-55.0$ & $\mathbf{1 , 2 9 0}$ & 1.75 & 763 & 1.24 & -527 & -40.85 \\
$55.5-60.0$ & $\mathbf{1 , 7 2 0}$ & 2.34 & 1,554 & 2.52 & -166 & -9.65 \\
$61.0-65.0$ & $\mathbf{3 , 1 5 0}$ & 4.28 & 2,253 & 3.66 & -897 & -28.48 \\
$65.5-70.0$ & $\mathbf{6 , 2 7 0}$ & 8.52 & 4,284 & 6.96 & $-1,986$ & -31.67 \\
$71.0-75.0$ & $\mathbf{1 0 , 2 9 0}$ & 13.99 & 8,283 & 13.46 & $-2,277$ & -19.50 \\
$75.5-80.0$ & $\mathbf{1 4 , 2 6 0}$ & 19.39 & 12,854 & 20.88 & $-1,406$ & -9.86 \\
$81.0-85.0$ & $\mathbf{1 4 , 7 7 0}$ & 20.08 & 11,826 & 19.21 & $-2,944$ & -19.93 \\
$85.5-90.0$ & $\mathbf{1 1 , 2 2 0}$ & 15.25 & 9,025 & 14.66 & $-2,195$ & -19.56 \\
$91.0-95.0$ & $\mathbf{6 , 2 2 0}$ & 8.46 & 6,798 & 11.05 & +578 & +8.50 \\
$95.5-100$ & $\mathbf{3 , 0 9 0}$ & 4.20 & 2,977 & 4.84 & -113 & -3.66 \\
\hline Total & $\mathbf{7 3 , 5 6 0}$ & & 61,547 & & 12,013 & -16.33
\end{tabular}




\section{Acknowledgements:}

The research reported on in this paper has been supported, in part, by an Australian Research Council Discovery Grant (\#DP1095497) and uses unit record data from the Household, Income and Labour Dynamics in Australia (HILDA) Survey. The HILDA Project was initiated and is funded by the Australian Government Department of Families, Housing, Community Services and Indigenous Affairs (FaHCSIA) and is managed by the Melbourne Institute of Applied Economic and Social Research (Melbourne Institute). The findings and view reported in this paper, however, are those of the authors and should not be attributed to FaHCSIA or the Melbourne Institute. We thank Ann-Marie James for her assistance in the preparation of this manuscript. We also thank Robert Connor and Linda Hartley-Clark for their suggestions regarding the text. 


\section{References}

Andrews, F. M., \& Withey, S. B. (1976). Social indicators of well-being: American's perceptions of life quality. New York: Plenum Press.

Block, J. (1981). Some enduring and consequential structures of personality. In A. I. Rabin, J. Aronoff, A. M. Barclay \& R. A. Zucker (Eds.), Further Explorations in Personality (pp. 27-43). New York: Wiley.

Blore, J. D., Stokes, M. A., Mellor, D., Firth, L., \& Cummins, R. A. (2011). Comparing multiple discrepancies theory to affective models of subjective wellbeing. Social Indicators Research, 100, 1-16. doi: 10.1007/s11205-010-9599-2

Brickman, P., \& Campbell, D. T. (1971). Hedonic relativism and planning the good society. In M. H. Appley (Ed.), Adaptation-level theory: A symposium (pp. 287-302). New York: Academic Press.

Brickman, P., Coates, D., \& Janoff-Bulman, R. (1978). Lottery winners and accident victims: Is happiness relative? Journal of Personality and Social Psychology, 36, 917-927.

Brim, G., \& Kagan, J. (1980). Constancy and Change in Human Development. Cambridge: Harvard University Press.

Cannon, W. B. (1932). The wisdom of the body. New York NY: Norton.

Clark, A. E., Diener, E., Georgellis, Y., \& Lucas, R. E. (2008). Lags and leads in life satisfaction: A test of the baseline hypothesis. Economic Journal, 118, F222-F243. doi: 10.1111/j.1468-0297.2008.02150.x

Costa, P. T., \& McCrae, R. (1980). Influence of extraversion and neuroticism on subjective well-being: Happy and unhappy people. Journal of Personality and Social Psychology, 38, 668-678.

Costa, P. T., \& McCrae, R. R. (1984). Personality as a lifelong determinant of wellbeing. In C. Z. Malatesta \& C. E. Izard (Eds.), Emotion in adult development (pp. 141-157). Beverly Hills: Sage Publications.

Cummins, R. A. (1995). On the trail of the gold standard for life satisfaction. Social Indicators Research, 35, 179-200. doi: 10.1007/BF01079026 
Cummins, R. A. (1998). The second approximation to an international standard of life satisfaction. Social Indicators Research, 43, 307-334. doi: 10.1023/A:1006831107052

Cummins, R. A. (2000). Personal income and subjective well-being: A review. Journal of Happiness Studies, 1, 133-158.

Cummins, R. A. (2010). Subjective wellbeing, homeostatically protected mood and depression: A synthesis. Journal of Happiness Studies, 11, 1-17. doi: 10.1007/s10902009-9167-0

Cummins, R. A., Lau, A. D. L., \& Davern, M. (2012). Subjective wellbeing homeostasis. In K. C. Land, A. Michalos \& J. Sirgy (Eds.), Handbook of social indicators and quality-of-life studies. Volume I: Theoretical and Methodological Foundations (pp. 79-98). New York: Springer.

Cummins, R. A., Woerner, J., Gibson, A., Lai, L., Weinberg, M., \& Collard, J. (2008). Australian Unity Wellbeing Index: - Report 19.0. The Wellbeing of Australians Links with exercise, nicotine and alcohol Retrieved September 26, 2012, from http://www.deakin.edu.au/research/acqol/index_wellbeing/index.htm

Cummins, R. A., Woerner, J., Hartley-Clark, L., Perera, C., Collard, J., \& Horfiniak, K. C. (2011). Australian Unity Wellbeing Index - Report 26.0 - The Wellbeing of Australians - Chronic health. Retrieved September 26, 2012, from http://www.deakin.edu.au/research/acqol/index_wellbeing/index.htm

Davern, M., Cummins, R. A., \& Stokes, M. (2007). Subjective wellbeing as an affective/cognitive construct. Journal of Happiness Studies, 8, 429-449. doi: 10.1007/s10902-007-9066-1

Deinzer, R., Steyer, R., Eid, M., Notz, P., Schwenkmezger, P., Ostendorf, F., \& Neubauer, A. (1995). Situational effects in trait assessment: The FPI, NEOFFI, and EPI questionnaires. European Journal of Personality, 9, 1-23.

Diener, E., \& Diener, C. (1996). Most people are happy. Psychological Science, 7, 181-185.

Diener, E., Lucas, R. E., \& Scollon, C. N. (2006). Beyond the hedonic treadmill: Revising the adaptation theory of well-being. American Psychologist, 61, 305-314. doi:

10.1037/0003-066X.61.4.305

Eid, M., \& Diener, E. (2004). Global judgments of subjective well-being: Situational variability and long-term stability. Social Indicators Research, 65, 245-278. 
Frederick, S., \& Loewenstein, G. (1999). Hedonic adaptation. In D. Kahneman, E. Diener \& N. Schwarz (Eds.), Well-being: The foundations of hedonic psychology (pp. 302-329). New York: Russell Sage Foundation.

Frijters, P., Johnston, D. W., \& Shields, M. A. (2011). Life satisfaction dynamics with quarterly life event data. Scandinavian Journal of Economics, 113, 190-211. doi: 10.1111/j.1467-9442.2010.01638.x

Fujita, F., \& Diener, E. (2005). Life satisfaction set point: Stability and change. Journal of Personality and Social Psychology, 88, 158-164. doi: 10.1037/0022-3514.88.1.158

Hartmann, G. W. (1934). Personality traits associated with variations in happiness. Journal of Abnormal and Social Psychology, 29, 202-212.

Headey, B. (2010). The set point theory of well-being has serious flaws: On the eve of a scientific revolution. Social Indicators Research, 97, 7-21. doi: 10.1007/s11205-0099559-X

Headey, B., Muffels, R., \& Wagner, G. G. (2010). Long-running German panel survey shows that personal and economic choices, not just genes, matter for happiness. PNAS, 107, 17922-17926. doi: 10.1073/pnas.1008612107

Headey, B., Muffels, R., \& Wagner, G. G. (2012). Choices which change life satisfaction: Similar results for Australia, Britain and Germany. Social Indicators Research. doi: $10.1007 / \mathrm{s} 11205-012-0079-8$

Headey, B., \& Wearing, A. (1989). Personality, life events, and subjective well-being: Toward a dynamic equilibrium model. Journal of Personality and Social Psychology, 57, 731-739. doi: 10.1037/0022-3514.57.4.731

Headey, B., \& Wearing, A. (1992). Understanding happiness: A theory of subjective wellbeing. Melbourne: Longman Cheshire.

Jackson, D. N., \& Paunonen, S. V. (1980). Personality structure and assessment. Annual Review of Psychology, 31, 503-552.

Keesey, R. E., \& Powley, T. L. (1986). The regulation of body weight. Annual Review of Psychology, 37, 109-133.

Keyes, C. L. M., Myers, J. M., \& Kendler, K. S. (2010). The structure of the genetic and environmental influences on mental well-being. American Journal of Public Health, $100,2379-2384$. 
Lucas, R. E. (2005). Time does not heal all wounds: A longitudinal study of reaction and adapation to divorce. Psychological Science, 16, 945-950. doi: 10.1111/j.14679280.2005.01642.x

Lucas, R. E. (2007). Long-term disability is associated with lasting changes in subjective well-being: Evidence from two nationally representative longitudinal studies. Journal of Personality and Social Psychology, 92, 717-730. doi: 10.1037/0022-3514.92.4.717

Lucas, R. E., Clark, A. E., Georgellis, Y., \& Diener, E. (2004). Unemployment alters the set point for life satisfaction. Psychological Science, 15, 8-13. doi: 10.1111/j.09637214.2004.01501002.x

Lykken, D., \& Tellegen, A. (1996). Happiness is a stochastic phenomenon. Psychological Science, 7, 186-189.

McGue, M., Bacon. S., \& Lykken, D. T. (1993). Personality stability and change in early adulthood: A behavioral genetic analysis. Developmental Psychology, 29, 96-109. doi: $10.1037 / 0012-1649.29 .1 .96$

Murrell, S. A., \& Himmelfarb, S. (1989). Effects of attachment bereavement and pre-event conditions on subsequent depressive symptoms in older adults. Psychology and Aging, 4, 166-172.

Okun, M. A., Olding, R. W., \& Cohn, C. M. (1990). A meta-analysis of subjective well-being interventions among elders. Psychological Bulletin, 108, 257-266.

Oswald, A. J., \& Powdthavee, N. J. (2008). Does happiness adapt? A longitudinal study of disability with implications for economists and judges. Journal of Public Economics, 92, 1061-1077. doi: 10.1016/j.jpubeco.2008.01.002

Palmore, E., \& Kivett, V. (1977). Change in life satisfaction: A longitudinal study of persons aged 46-70. Journal of Gerontology, 32, 311-316.

Sailer, R. C. (1931). Happiness self-estimates of young men. Teachers College Contribution to Education, 467.

Scollon, C. N., \& Diener, E. (2006). Love, work, and changes in extraversion and neuroticism over time. Journal of Personality and Social Psychology, 91, 1152-1165. doi: 10.1037/0022-3514.91.6.1152

Smith, H. C. (1961). Personality adjustment. New York: McGraw-Hill. 
Tellegen, A., Lykken, D. T., Bouchard, T. J. J., Wilcox, K., Segal, N., \& Rich, S. (1988). Personality similarity in twins reared apart and together. Joumal of Personality and Social Psychology, 54, 1031-1039.

Tomyn, A. J., \& Cummins, R. A. (2011). Subjective wellbeing and homeostatically protected mood: Theory validation with adolescents. Journal of Happiness Studies, 12, 897914. doi: 10.1007/s 10902-010-9235-5

Watson, G. B. (1930). Happiness among adult students of education. Journal of Educational Psychology, 21, 79-109.

Watson, N., \& Wooden, M. (2002). The Household, Income and Labour Dynamics in Australia (HILDA) Survey: Wave 1 Survey Methodology HILDA Project Technical Paper Series No. 1/02. Retrieved from Melbourne Institute of Applied Economic and Social Research, University of Melbourne.

Watson, N., \& Wooden, M. (2012). The HILDA Survey: A Case Study in the Design and Development of a Successful Household Panel Study. Longitudinal and Life Course Studies.

Wessman, A. E., \& Ricks, D. F. (1966). Mood and personality. New York: Holt, Rinehart \& Winston.

Williams, D. E., \& Thompson, J. K. (1993). Biology and behavior: A set-point hypothesis of psychological functioning. Behavior Modification, 17, 43-57. doi: $10.1177 / 01454455930171004$

Wilson, W. (1967). Correlates of avowed happiness. Psychological Bulletin, 67, 294-306.

Wortman, C., \& Silver, R. (1982). Coping with undesirable life events. Paper presented at the Paper presented at the 90th Annual Convention of the American Psychological Association, Washington, DC. 